\title{
Mountain Climates and Climatic Change: An Overview of Processes Focusing on the European Alps
}

\author{
MARTIN BENISTON
}

\begin{abstract}
This contribution provides an overview of the intricacies of mountain climates, particularly as they pertain to the European Alps. Examples will be given of issues that are related to climatic change as observed in the Alps during the course of the 20th century, and some of the physical mechanisms that may be responsible for those changes. The discussion will then focus on the problems related to assessing climatic change in regions of complex topography, the potential shifts in climate during the 21 st century that the alpine region may be subjected to, and the associated climate-generated impacts on mountain environments.
\end{abstract}

Key words: Climate, climatic change, modeling, North Atlantic Oscillation, snow, mountain regions.

\section{Introduction}

Significant orographic features occupy close to $25 \%$ of continental surfaces (KAPOS et al., 2000) and, although only about $26 \%$ of the world's population resides within mountains or in the foothills of the mountains (MEYBECK et al., 2001), mountain-based resources indirectly provide sustenance for over half. This is principally because over $40 \%$ of the global population lives in the watersheds of rivers originating in the planet's different mountain ranges (BENISTON, 2000).

Although mountains differ considerably from one region to another, one common feature is the complexity of their topography. Orographic features include some of the sharpest gradients found in continental areas. Related characteristics include rapid and systematic changes in climatic parameters, in particular temperature and precipitation, over very short distances (BECKER and BUGMANN, 1997); greatly enhanced direct runoff and erosion; systematic variation of other climatic (e.g., radiation) and environmental factors (e.g., differences in soil types). Mountains in many parts of the world are susceptible to the impacts of a rapidly changing climate, and provide interesting locations for the early detection and study of the

\footnotetext{
${ }^{1}$ Department of Geosciences, University of Fribourg, Chemin du Musé 4, CH-1700, Fribourg, Switzerland. E-mail: Martin.Beniston@unifr.ch
} 
signals of climatic change and its impacts on hydrological, ecological, and societal systems.

This paper will present an overview of the intricacies of mountain climates, particularly as they pertain to the European Alps. The Alps are without question one of the best-endowed mountain ranges in terms of data availability for studies related to climate and the environment. Examples will be given of issues that are related to climatic change as has already occurred in the Alps during the course of the $20^{\text {th }}$ century, and the physical mechanisms that are responsible for the observed changes. In a final part, the potential shifts in climate during the $21^{\text {st }}$ century in the alpine region will be reviewed, along with the possible impacts on mountain environments that these changes could generate.

\section{Specificities of Mountain Climates}

Climate is the principal factor governing the natural environment of mountains on short time scales, and characterizes the location and intensity of biological, physical and chemical processes. Mountain climates are determined by four major factors, namely continentality, latitude, altitude, and features related to topography itself (BARRY, 1994).

Continentality refers to the proximity of a particular region to an ocean. The diurnal and annual ranges of temperatures in a maritime climate are markedly less than in regions far removed from the oceans; this is essentially due to the large thermal capacity of the sea, which warms and cools far less rapidly than land. Because the ocean represents a large source of moisture, there is also more precipitation in a maritime climate than in a continental one, provided the dominant wind direction is onshore. Examples of maritime mountain climates include the Cascade Ranges in Oregon and Washington States of the United States, the Alaskan coastal mountains, the New Zealand Alps, the Norwegian Alps, and the southern Chilean Andes. Mountains under the dominant influence of continental-type climates include the Tibetan Plateau, the mountains of Central Asia (Pamir, Tien Shan, Urals), and the Rocky Mountains in the western states of the United States. However, many other mountain regions often define and separate climatic regions; for example, the European Alps act as a boundary between Mediterranean-type, Atlantic, and continental climates.

While mountains in continental regions experience more sunshine, less precipitation, and a larger range of temperatures than maritime mountains, they are not necessarily harsher environments. For certain ecosystems, the larger amounts of sunshine compensate for lower mean temperatures in continental regions. Increased cloudiness and precipitation (both rain and snow) in coastal mountain ranges such as the Cascades or the New Zealand Alps limit the growth of certain species despite the milder overall temperatures. The timberline in continental regions is often located at 
higher elevations than in maritime zones, which confirms the importance of these compensating factors for regional ecological systems (WARDLE, 1973; WADE and MCVEAN, 1969).

Latitude determines to a large extent the amplitude of the annual cycle of temperature and, to a lesser extent, the amount of precipitation that a region experiences. Mountains tend to amplify some of the characteristics of tropical, midlatitude and boreal climates for reasons related to topography. Altitude, however, is certainly the most distinguishing and fundamental characteristic of mountain climates. Atmospheric density, pressure and temperature decrease with height in the troposphere. At high elevations, thermal conditions are often extreme; the only source of energy is the direct solar radiation that is absorbed by the surface. Mountain soils can heat up rapidly during the day, and exchange some of this heat with the air in contact with the surface, but because of the lack of air and water vapor molecules, only a very thin envelope of air is likely to be warmed. This leads to steep vertical temperature gradients in the first few meters above the ground. Mountains serve in this sense as elevated heat sources, whereby diurnal temperatures are higher than at similar altitudes in the free atmosphere (FLOHN, 1968). The diurnal and annual range of temperature tends to decrease with altitude because of the lower heat capacity of the atmosphere at higher elevations. The altitudinal controls on mountain climates also exert a significant influence on the distribution of ecosystems. Indeed, there is such a close link between mountain vegetation and climate that vegetation belt typology has been extensively used to define climatic zones and their altitudinal and latitudinal transitions (for example KLÖTZLI, 1994; OzENDA, 1985; Quezel and BARBERo, 1990; RAMEAU et al., 1993).

Mountain systems generate their own climates (EKHART, 1948), as a function of the size of the land mass at a particular elevation. Topographic features also play a key role in determining local climates, in particular due to the slope, aspect, and exposure to climatic elements. These factors tend to govern the redistribution of solar energy as it is intercepted at the surface, as well as precipitation that is highly sensitive to local site characteristics. In many low and mid-latitude regions, precipitation is observed to increase with height; even modest topographic elements can exert an often disproportionate influence on precipitation amount. Precipitation mechanisms are linked to atmospheric dynamics and thermodynamics. When a mass of moist air is forced to rise above the condensation level, the excess vapor is converted to fine liquid water particles that become visible in the form of mist, fog or clouds. If uplift of air continues, then precipitation processes will be triggered if sufficient liquid water or ice crystals are available.

Precipitation in a mountain region will generally fall out on the windward-facing slopes of the mountains because of the dynamics associated with uplift. Because most of the moisture is extracted from the clouds on the windward slopes, the air that crosses over to the lee side of the mountains is essentially dry. Clouds may form and appear to adhere to the mountain crests, but little precipitation is likely to fall on the 
leeward sides of the mountains. Death Valley in California, one of the most arid desert regions in the world, is located on the leeward side of the highest part of the Californian Sierra Nevada range. Indeed, most of the desert regions of the western United States lie to the east of the coastal ranges that are located close to the Pacific coasts of North America. Precipitation gradients are steep from one side of the ranges to the other; for example, San Francisco, California receives an average of $475 \mathrm{~mm}$ of precipitation annually (double or triple that amount falls in the upper reaches of the Sierra Nevadas), while Las Vegas, Nevada receives only $99 \mathrm{~mm}$. On more local scales, the windward and leeward influences on precipitation are particularly marked on islands which have a significant orography; the main city of Big Island, Hawaii (Hilo) experiences close to 3,500 $\mathrm{mm}$ annually, while the resort areas of Kailua-Kona, situated in the lee of the 4,000 m Mauna Laua and Mauna Kea volcanoes, receive only a sparse annual $65 \mathrm{~mm}$.

As in many other cases of environmental stress, exogenous factors contribute to the overall environmental impacts in mountains and uplands. Air pollution is one such stress factor that has a number of ecological consequences, because it is so readily transported by atmospheric circulations from the emission sources to the receptor areas. The distances covered by chemical compounds in the atmosphere can cover large distances, according to the type of pollutant, its chemical reactivity and the dominant airflows in which they are embedded. As a result, particulate matter or acidic compounds can be detected in remote mountain regions which are far removed from their source regions.

$\mathrm{NO}_{2}$ is one of the precursor gases of ozone $\left(\mathrm{O}_{3}\right)$, which is a highly corrosive and toxic gas that damages plants and leads to respiratory and ocular problems at sufficiently high concentrations. Ground-level ozone is not emitted directly into the atmosphere, but is a secondary pollutant produced by reaction between nitrogen dioxide $\left(\mathrm{NO}_{2}\right)$, hydrocarbons and sunlight. Whereas nitrogen dioxide $\left(\mathrm{NO}_{2}\right)$ participates in the formation of ozone, nitrogen oxide (NO) destroys ozone to form oxygen $\left(\mathrm{O}_{2}\right)$ and nitrogen dioxide $\left(\mathrm{NO}_{2}\right)$. For this reason, ozone levels are not as high in urban zones (where high levels of NO are emitted from vehicles) as in non-urban areas. As the nitrogen oxides and hydrocarbons are transported out of urban regions, the ozone-destroying $\mathrm{NO}$ is oxidized to $\mathrm{NO}_{2}$, which participates in ozone formation. Ozone can therefore be present in mountain areas located at considerable distances from the source regions of the ozone precursors. Ozone is possibly one of the factors responsible for forest dieback in the European Alps for example, where damage to trees is believed to be linked to heavy industrial sites at the boundaries of the mountains, as in northern Italy. As always with environmental threats, the large time lag between load and full reaction, where ecosystems and soils are involved, has probably still not reached the peak impact.

GRASSL (1994) has shown that there has been an upward trend in tropospheric ozone concentrations at Alpine sites, such as the Zugspitze, at $2950 \mathrm{~m}$ altitude in Germany, since measurements began in the late 1960s. In contrast, ozone levels at 
the nearby urban site of Garmisch-Partenkirchen have not risen (SCHNEIDER, 1992), typically due to the ozone-destroying chemical reactions taking place in an urban environment with a high density of motorized traffic. Since sunlight is a prerequisite for the physico-chemical transformation of $\mathrm{NO}$ and $\mathrm{NO}_{2}$ into $\mathrm{O}_{3}$, high levels of ozone are generally observed during periods of persistently warm weather, and in locations where poor ventilation allows concentrations of hydrocarbons and nitrogen oxides to reach critical levels. Because of the time required for chemical processing, ozone formation tends to take place downwind of pollution centers. The resulting ozone pollution or "summertime smog" may persist for several days and be transported over long distances.

Sulfur contained in coal, which is used in many industrial processes worldwide for energy transformations, smelting, etc., is released into the atmosphere in the form of sulfur dioxide $\left(\mathrm{SO}_{2}\right)$. This can then be dissolved in liquid water droplets in clouds and fog to form sulfuric acid $\left(\mathrm{H}_{2} \mathrm{SO}_{4}\right)$, which is then transported in atmospheric flows and ultimately falls to the surface in a process known as acid deposition or acid rain, with a number of adverse environmental consequences. Acidification of soils damages vegetation and releases heavy metals such as aluminium, copper or mercury into hydrological systems; these toxic metals are absorbed by fish and other aquatic species, with potentially serious consequences for the food chain. The interactions between living organisms and the chemistry of their aquatic habitats are extremely complex. If the number of one species or group of species changes in response to acidification, then the ecosystem of the entire water body is likely to be affected through predator-prey relationships. Terrestrial animals dependent on aquatic ecosystems for their food supply, such as birds, are also affected.

In the European Alps, the consequences of acid precipitation may be exacerbated in many regions by the fact that precipitation increases with altitude. SMIDT (1991) has shown that for two Austrian alpine sites contamination of precipitation with ions resulting from pollution decreases with altitude, but deposition increases because of enhanced precipitation with height. Since the concentration of basic anions and cations in precipitation is rather uniform over central Europe, the Alps are subject to as much acid deposition as other areas because of the orographic controls on precipitation, despite the fact the Alps are not in themselves a major source of sulfate-based pollutants.

Future trends in pollution and its long-distance transport are difficult to assess. On the one hand, increasing industrialization has the potential of generating high levels of pollution. On the other hand, the awareness that pollution is detrimental to human health and the environment has led to policies aimed at controlling emissions, particularly in western Europe, and thus the additional impacts on the Alps may be limited. 


\section{Shifts in Alpine Climates during the $20^{\text {th }}$ Century}

The climate of the Alpine region is characterized by a high degree of complexity, due to the interactions between the mountains and the general circulation of the atmosphere, which result in features such as gravity wave breaking, blocking highs, and föhn winds. A further cause of complexity inherent to the Alps results from the competing influences of a number of different climatological regimes in the region, namely Mediterranean, Continental, Atlantic, and Polar.

Figure 1 shows the changes in yearly mean surface temperature anomalies in the course of the $20^{\text {th }}$ century from the 1961-1990 climatological mean, averaged for eight sites in Switzerland (namely Altdorf, Basel, Bern, Davos, Lugano, Neuchâtel, Säntis and Zürich). The global data discussed in Jones and MobERG (2003) have been superimposed here to illustrate the fact that the interannual variability in the Alps is higher than on a global or hemispheric scale; the warming experienced since the early 1980s, while synchronous with global warming, is of far greater amplitude and exceeds $1.5^{\circ} \mathrm{C}$ for this ensemble average. This represents roughly a three-fold amplification of the global climate signal in the Alps (DIAZ and BRADLEY, 1997).

Closer investigation reveals that climatic change in the alpine region during the $20^{\text {th }}$ century has been characterized by increases in minimum temperatures of up to $2{ }^{\circ} \mathrm{C}$, a more modest increase in maximum temperatures, little trend in the precipitation data, and a general decrease of sunshine duration through to about the mid-1980s (BENISTON, 2000). Several periods of warming can be observed during the instrumental record, with the 1940s exhibiting a particularly strong warming and

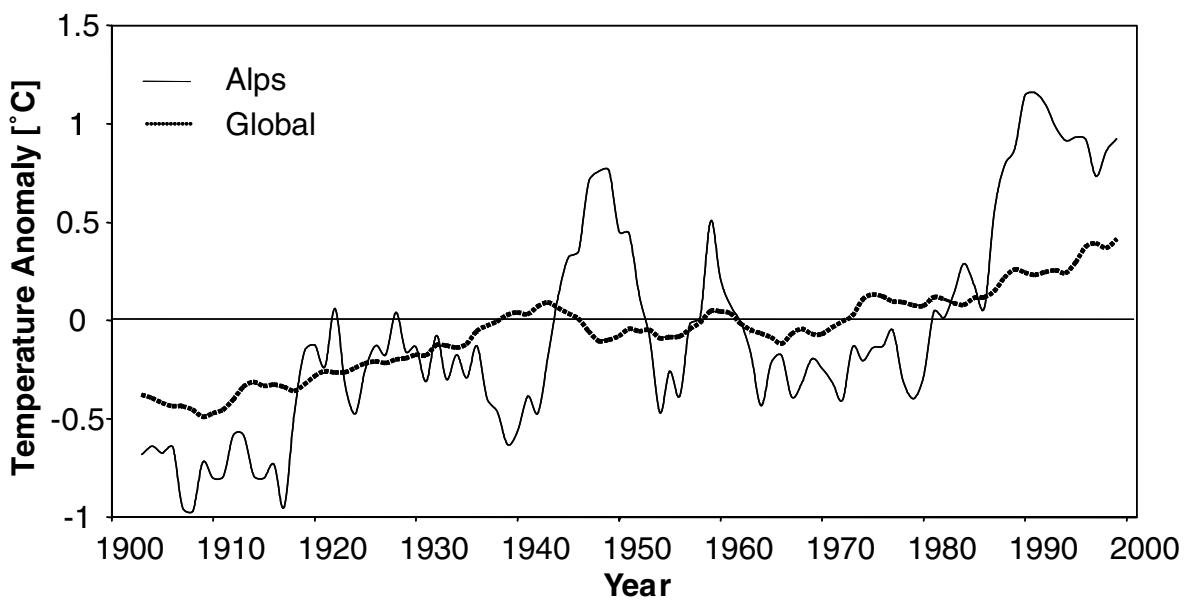

Figure 1

Temperature departures from the 1961-1990 climatological mean in the Swiss Alps compared to global temperature anomalies, for the period 1901-2000. A five-year filter has been applied to remove interannual noise (BENISTON et al., 1997). 
then a cooling into the 1950s. The most intense warming occurs in the 1990s, however (JUNGO and BENISTON, 2001), which can be explained in part by the behavior of the North Atlantic Oscillation (NAO; BENISTON and JungO, 2002). This phenomenon is a large-scale alternation of atmospheric pressure fields (i.e., atmospheric mass), whose centers of action are near the Icelandic Low and the Azores High. One mode of the NAO is when sea-level pressure is lower than normal in the Icelandic low pressure center, it is higher than normal near the Azores, and viceversa, hence the notion of an oscillatory behavior of the system. Another possible mode occurs when pressures also rise or fall simultaneously in both centers of meteorological activity, but in this case the NAO signal is not quite as strong. The NAO index is a normalized pressure difference between the Azores (or Lisbon, Portugal) and Iceland; it is a measure of the intensity of zonal flow across the North Atlantic and the associated position of storm tracks and regions of strongest storm intensity. This flow is itself driven by the temperature (and hence pressure) contrasts between polar and tropical latitudes.

The NAO represents one of the most important modes of decadal-scale variability of the climate system after ENSO (El Niño/Southern Oscillation), and accounts for up to $50 \%$ of sea-level pressure variability on both sides of the Atlantic (HuRRel, 1995). It has been observed to strongly influence precipitation and temperature patterns on both the eastern third of North America and western half of Europe; the influence of the NAO is particularly conspicuous during winter months. It was shown in recent years (BENISTON et al., 1994; HurRel, 1995; Rogers, 1997;

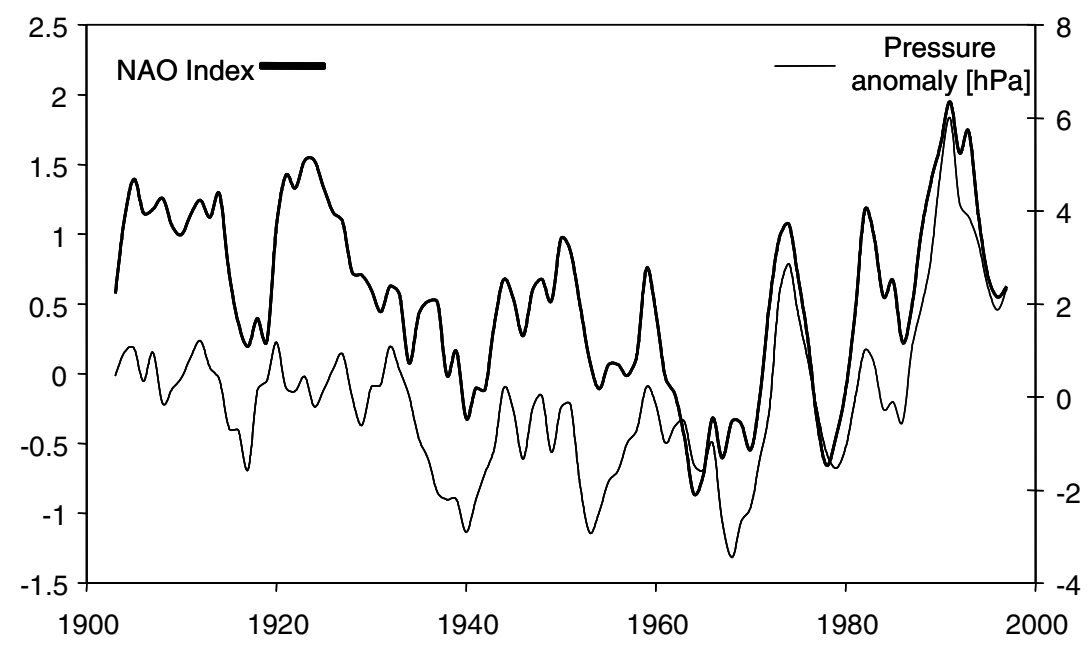

Figure 2

$20^{\text {th }}$ Century time series of the wintertime (DJF) index of the North Atlantic Oscillation (NAO) and surface pressure anomalies at Säntis (2,500 m above sea-level). A 5-point filter is used to eliminate highfrequency oscillations in the series (BENISTON and JUNGO, 2002). 
SERREZE et al., 1997) that a significant fraction of climatic anomalies observed on either side of the Atlantic are driven by the behavior of the NAO.

BENISTON (2000) has shown that temperature, moisture and pressure trends and anomalies at high elevations stand out more clearly than at lower levels, where boundary-layer processes, local site characteristics and urban effects combine to damp the large-scale climate signals. Climatic processes at high elevation sites can thus in many instances be considered to be the reflection of large-scale forcings, such as the NAO. These findings have been confirmed through numerical experimentation by Giorgi et al. (1997), who have underlined the altitudinal dependency of the regional atmospheric response to large-scale climatic forcings.

Figure 2 depicts the time series of the wintertime NAO index during the $20^{\text {th }}$ century, and the associated surface wintertime (December-January-February; DJF) pressure anomalies in Zürich, based on the 30-year climatological average period 1961-1990; a 5-point filter has been applied to both curves in order to remove the higher-frequency fluctuations for the purposes of clarity. Average pressure values, even at a single site, can be considered to be a measure of synoptic-scale conditions influencing the Alpine region, as discussed in BENISTON et al. (1994). The pressure measured at Zürich or elsewhere, when averaged on a seasonal or longer time span, is therefore representative of the large-scale pressure field over Switzerland. The very close relationship between the two curves in Figure 2 highlights the subtle linkages between the large-scale NAO forcings and the regional-scale pressure response over Switzerland. When computed for 1901-1999, 56\% of the observed pressure variance in Switzerland can be explained by the behavior of the NAO. From 1961-1999, this

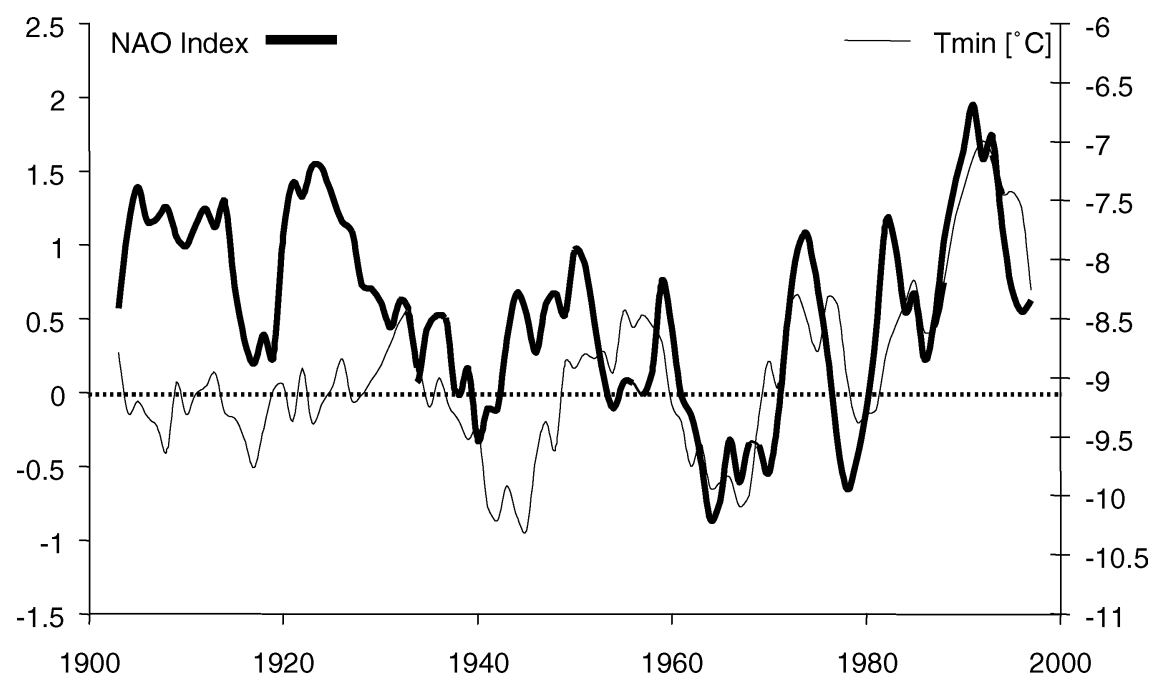

Figure 3

As Figure 2, except for DJF minimum temperature time series (BENISTON and JUNGO, 2002). 
figure rises to $83 \%$, which is considerable bearing in mind the numerous factors that can also determine regional pressure fields. WANNER et al. (1997) speculate that the persistent Alpine high pressure observed in the 1980s and early 1990s is linked to rising NAO index values through a northern shift of the upper-level jet stream associated with the polar front. When this occurs, the Alps lie to the right exit zone of the diverging jet streamlines, and are thus subject to mass influx and hence positive pressure tendencies.

Figure 3 illustrates the relation between the wintertime NAO index and the DJF temperature time series for Zürich, where both curves are smoothed as in Figure 2. As for pressure trends, the synchronous behavior between temperature and the NAO is striking, particularly in the second half of the $20^{\text {th }}$ Century, where the minimum temperature variance which can be accounted for by the NAO fluctuations from 1961-1999 exceeds $72 \%$.

A particular feature of the positive phase of the NAO index is that it is invariably coupled to anomalously low precipitation and milder than average temperatures, particularly from late fall to early spring, in southern and central Europe (including the Alps and the Carpathians), while the reverse is true for periods when the NAO index is negative. As an illustration of the impacts of NAO behavior on the seasonality and quantity of snow in the Alps, BenISTON (1997) has shown that periods with relatively low snow amounts are closely linked to the presence of persistent high surface pressure fields over the Alpine region during late Fall and through to early Spring. In his 1997 paper, Beniston discussed a number of recurring links between the NAO and winter temperature and precipitation characteristics; in general, strongly positive NAO leads to persistent high pressure over the alpine region, resulting in warmer than average temperatures and lower than average precipitation, because of the fact that Atlantic storms track much further to the north than when the NAO is less strongly positive. Since the mid-1980s and until 1996, the length of the snow season and the general quantities of snow amount decreased substantially in the Alps, as a result of pressure fields which were far higher and more persistent than at any other time during the $20^{\text {th }}$ century, as shown in Figure 4, from Beniston, (1997). Here, the pressure data is from Zürich which, though not in the same location as the two alpine sites, is nevertheless representative of a large-scale weather anomaly over the entire alpine region.

In order to highlight the possible relationships of high or low NAO index values with shifts in the frequency distributions of climate variables such as pressure, temperature and moisture, two thresholds for the wintertime NAO index have been chosen, namely the lower and upper 10 percentiles of the NAO index distribution during the $20^{\text {th }}$ century (i.e., the $10 \%$ and $90 \%$ thresholds, which correspond roughly to index values around -1.5 and +2.0 , respectively). These thresholds are representative of two highly contrasting synoptic regimes affecting the Alps, namely above-average pressure and associated positive temperature and negative moisture anomalies when the threshold is above the $90 \%$ level, and lower than average 


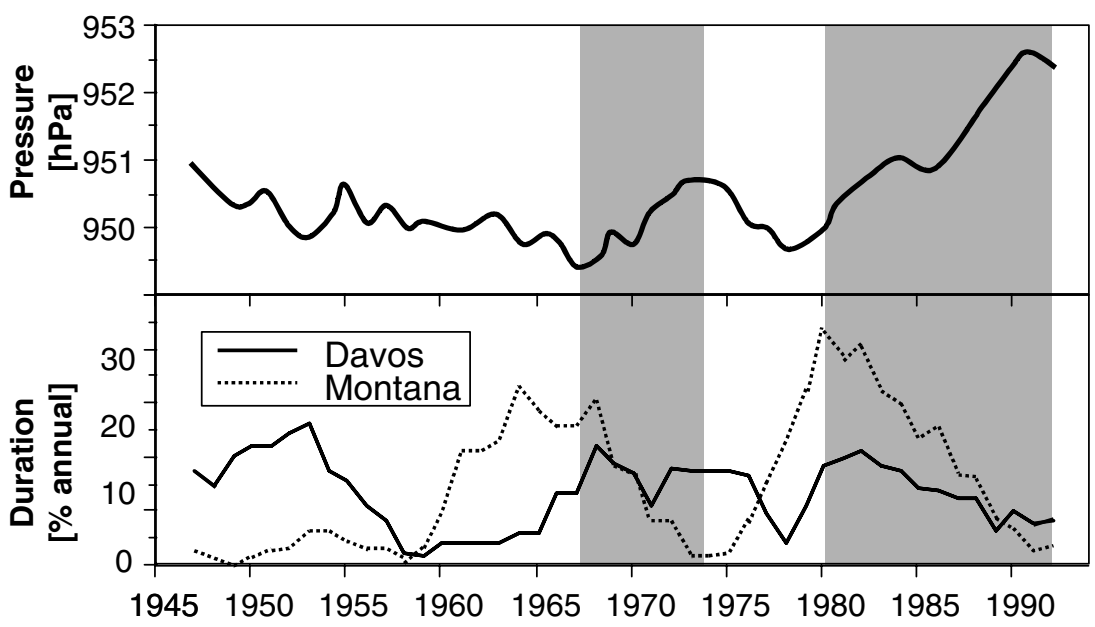

Figure 4

50-year time series of mean winter pressure (upper) and duration of winter snow cover at two alpine sites, for a snow-depth threshold of $1 \mathrm{~m}$ (BENISTON, 1997).

pressure and its controls on temperature and humidity when the index is lower than the $10 \%$ level. The probability density functions (PDF) of pressure, maximum and minimum temperatures, and relative humidity, have been computed for periods where the NAO index is greater than the $90 \%$ threshold, and the temperature PDFs for winters where the NAO anomaly index is less than the $10 \%$ threshold.

Figure 5 illustrates the behavior of these pressure PDFs at Säntis (a high elevation site in NE Switzerland, located at 2,500 $\mathrm{m}$ above sea-level), computed for periods of the $20^{\text {th }}$ century where the NAO index exceeds the upper threshold $(90 \%)$, or is inferior to the lower threshold $(10 \%)$. A substantial shift towards significantly higher pressures is observed for periods when the NAO index exceeds the $90 \%$ threshold; the PDF curve is translated to the right of the diagram, with a change in both the skewness and kurtosis of the distribution. Similar to the changes in pressure PDF, minimum temperatures exhibit a shift from the extreme low to the extreme high tails of the distribution (results not shown here). The changes are conspicuous at most observation sites in Switzerland. At Säntis, for example, the extreme low tails of the minimum temperature distribution disappear during periods of high NAO index, in favor of much warmer temperatures. Temperatures below $-15^{\circ} \mathrm{C}$ at Säntis, which account for roughly $30 \%$ of the winters where the NAO index is below the $10 \%$ level, occur only $15 \%$ of the time in winter months that experience high NAO values. This implies that the periods with extreme cold conditions are reduced by $50 \%$. Conversely, temperatures at the upper end of the distribution, for example above $-5^{\circ} \mathrm{C}$ represent $12 \%$ of the winter days for low NAO values and $23 \%$ for high NAO values. The duration of milder temperatures at Säntis thus doubles when the NAO shifts from its low negative to its high positive phase. 


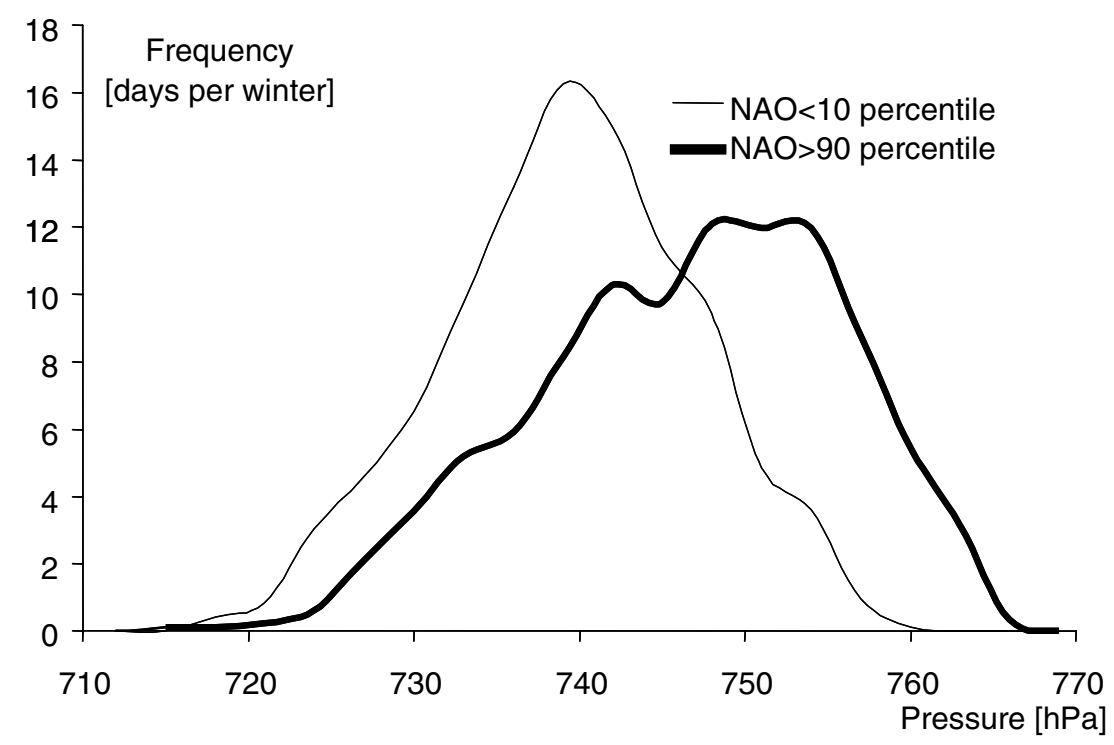

Figure 5

Probability density function of pressure at Säntis $(2,500 \mathrm{~m}$ above sea-level) for periods when the negative and positive NAO index thresholds are exceeded (BENISTON and JUNGO, 2002).

Similar conclusions can be reached for the distribution of $\mathrm{T}_{\max }$ (Fig. 6). This particular figure emphasizes the fact that the number of days in winter in which

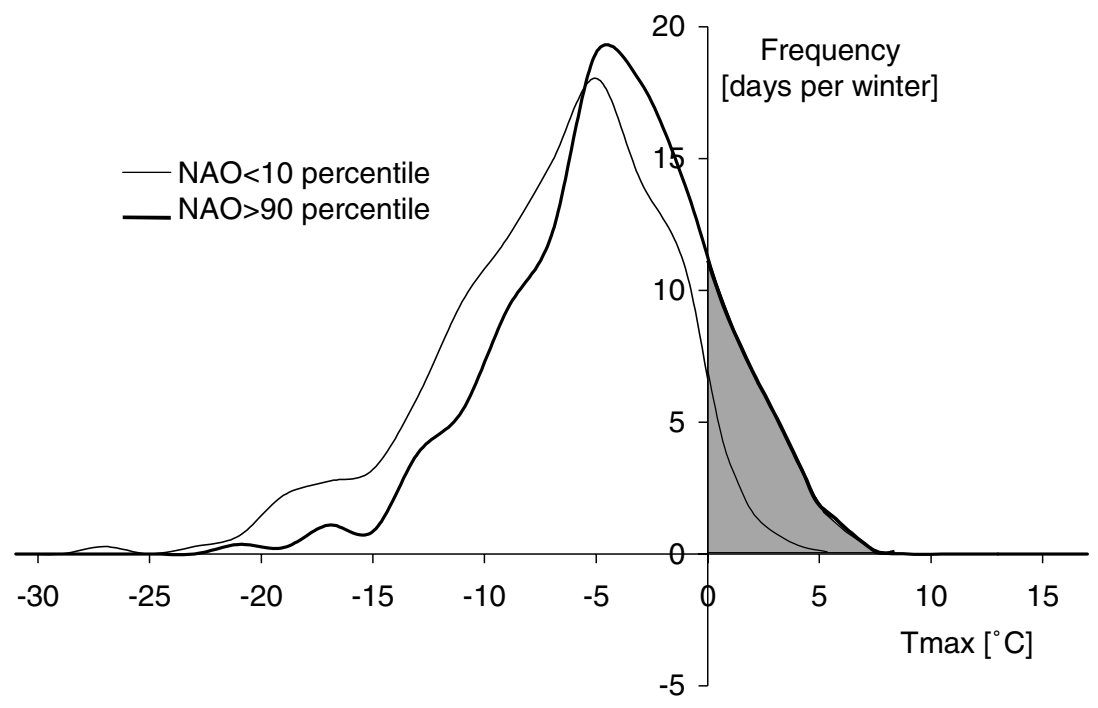

Figure 6

As Figure 5, except for maximum temperature PDF. Gray shading emphasizes PDF domain where temperatures exceed the freezing point (BENISTON and JUNGO, 2002). 
maximum temperatures exceed the freezing point range from 10 days for the lowermost NAO 10-percentile to 25 days for the uppermost NAO 10-percentile. This obviously has implications for physical variables such as snow amount and duration, and biologically-relevant factors such as the start of the vegetation period.

Moisture and precipitation in the alpine region are also influenced by the behavior of the NAO. In the case of the negative index threshold, over $50 \%$ of the values recorded in winter exceed $90 \%$ relative humidity, while in the case of the positive threshold this level of relative humidity is exceeded only $35 \%$ during the winter months (results not shown here). There is thus a clear reduction in ambient moisture at high elevations.

In the last decade, considerable interest has focused on the North Atlantic Oscillation, and it is sometimes used as an empirical predictor for precipitation and temperature in regions where climatic variables are well correlated with the NAO index. This is clearly seen to be the case in Northern and Southern Europe, while Central Europe and the Alps are generally a "pivot" around which the forcing of the NAO is amplified with distance north or south. While at low elevations, the NAO signal may be weak or absent in the Alps, higher elevation sites are on the contrary sensitive to changes in NAO patterns (BENISTON et al., 1994; BENISTON and REBETEZ, 1996; Hurrell, 1995; Hurrel and van LoOn, 1997; Giorgi et al., 1997). The processes associated with periods when the NAO index exceeds the $90 \%$ level include frequent blocking episodes, where pressure fields over the Alpine area are high, and vertical circulations induce subsiding air with associated compression warming. Such circulations invariably generate positive temperature anomalies, and reductions in moisture and precipitation. In addition, diurnal warming at high elevations is enhanced by above-average sunshine, since there is a lowering of cloud amount and duration during periods of blocking high pressures. The reverse is generally true for periods when the NAO index is below the 10-percentile of its distribution. It could be argued that nocturnal cooling should also be stronger in a cloud-free atmosphere, thus leading to lower minimum temperatures; however, in complex terrain, radiative cooling at night will lead to down slope flow and accumulation of cold air in the valleys. The nocturnal cooling effect is, proportionally, not as strong at mountain summits such as Säntis as further down in the valleys.

Such anomalies are not only reflected in the means of the analyzed climatic variables, but also — and perhaps especially — in their extremes. The previous section has shown that there are clear links between strongly positive or negative modes of the NAO, and extremes of pressure, temperature, and moisture; high NAO values systematically shift the distributions from the lower extremes to the upper extremes.

Since the early 1970s, and until 1996, the wintertime NAO index has been increasingly positive, indicative of enhanced westerly flow over the North Atlantic. This has led to synoptic situations in recent decades which have been associated with abundant precipitation over Norway, as cyclonic tracks enter Europe relatively far to 
the north of the continent (Hurrell, 1995). Over the Alpine region, on the other hand, positive NAO indices have resulted in surface pressure fields that have been higher than at any time this century. Investigations by BENISTON et al. (1994) concluded that close to $25 \%$ of the pressure episodes exceeding the $965 \mathrm{hPa}$ threshold recorded this century in Zürich (approximately $1030 \mathrm{hPa}$ reduced sea-level pressure) occured in the period from 1980-1992, with the four successive years from 1989-1992 accounting for $16 \%$ of this century's persistent high pressure in the region.

Table 1 shows an analysis of mean wintertime values for minimum and maximum temperatures, relative humidity and precipitation at Säntis for four distinct periods of the $20^{\text {th }}$ century, namely 1901-1999, 1950-1999, 1975-1999, and 1989-1999. In each case, the observed DJF mean is given, followed by the mean which would have occurred without the influence of highly-positive NAO index (beyond the 90percentile threshold). The third column for each variable represents the bias which NAO index exceeding the 90-percentile has imposed on temperature and moisture variables. It is seen in this Table that the bias is relatively small when considering the entire $20^{\text {th }}$ century (1901-1999), but then increases as one approaches the end of the $20^{\text {th }}$ century. In the last decade, from 1989-1999, the bias for minimum temperatures exceeds $1^{\circ} \mathrm{C}$. In the absence of the large forcings imposed by NAO index values greatrer than the 90-percentile, this decade would in fact have been slightly cooler in terms of minimum temperature than the average conditions observed between 1975 and 1999. Indeed, had there not been such a strong positive NAO forcing in the latter years of the $20^{\text {th }}$ century, minimum temperatures would not have risen by almost $1.5^{\circ} \mathrm{C}$ (decadal mean for the 1990s minus century mean from 1901-1999) but by less than $0.5^{\circ} \mathrm{C}$, as seen in the second column of the minimum temperature analyses. The bias imposed by strongly-positive NAO thresholds on maximum temperatures follows the same trends, but is not as high as for minimum temperatures; even in the absence of the NAO forcing, maximum temperatures would have risen substantially in the latter part of the $20^{\text {th }}$ century.

In terms of moisture, relative humidity has decreased in winter, with a bias of close to $10 \%$ in the period $1989-1999$, resulting from the NAO forcing; mean DJF relative humidity would have otherwise remained relatively constant throughout the century. Precipitation is also seen to be considerably marked by the NAO forcing in the last decade of the $20^{\text {th }}$ century, with a substantial drop of $20 \%$ of winter precipitation linked to the high and persistent NAO index recorded during this period.

Because over half of the NAO index values exceeding the 90-percentile have occurred since 1985, it may be concluded that the NAO is a significant driving factor for the climatic anomalies observed in recent years in the Alps. In particular, the highly anomalous nature of temperatures and their extremes that have been observed and discussed inter alia by JUNGO and BENISTON (2001) are largely explained by the large-scale influence on regional climate generated by the recent trends of the NAO. Removal of the biases imposed by high NAO episodes would have resulted in relatively modest increases in minimum temperatures and reduced rates of maximum 


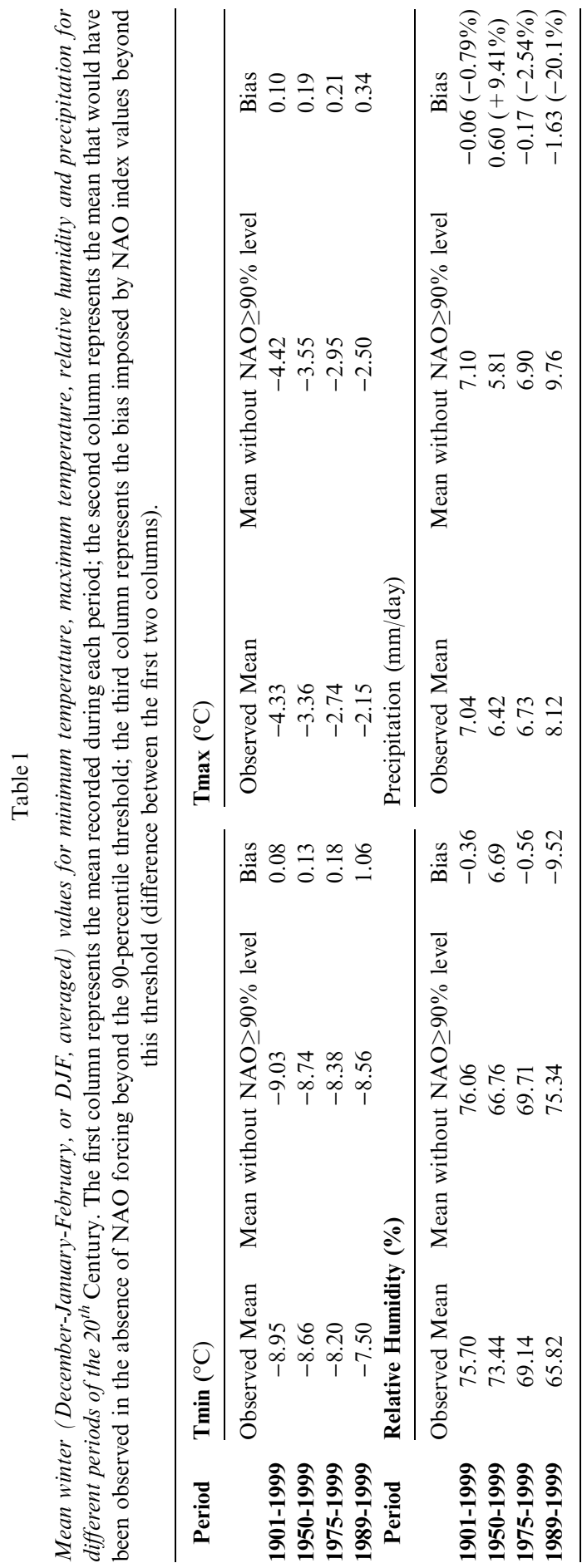


temperature warming, thus leading to Alpine-scale warming comparable to globalaverage warming (JONES and MOBERG, 2003).

\section{Future Climatic Change in the Alps}

General Circulation Model (GCM) simulations of the response of global climate to enhanced GHG concentrations have been a key focus of the IPCC reports (IPCC, 1996; 2001). Model simulations point to a warming which on a global average is in the range of $1.5-5.8^{\circ} \mathrm{C}$ in 2100 , depending on the scenario used. Scenarios of greenhouse-gas trajectories into the future are a complex mix of social, economic, political, and technological forecasts for the $21^{\text {st }}$ century. However, the complexity and mutual interdependency of mountain environmental and socio-economic systems pose significant problems for climate impacts studies (BENISTON et al., 1997). The assessment of current and future trends in regional climate is limited by the current spatial resolution of General Circulation Models (GCM) which is generally too crude to adequately represent the orographic detail of most mountain regions. On the other hand, most impacts research requires information at fine spatial resolution where the regional detail of topography or land-cover is an important determinant in the response of natural and managed systems to change. Since the mid-1990s, the scaling problem related to complex topography has been addressed through regional modeling techniques, pioneered by GIORGI and MEARNS (1991), and through statistical-dynamical downscaling techniques (e.g., ZORITA and VON STORCH, 1999).

So-called "nested" approaches to regional climate simulations, whereby largescale data or GCM outputs are used as boundary and initial conditions for regional climate model (RCM) simulations, have been applied to future climatic change in the course of the $21^{\text {st }}$ century (GIORGI and MEARNS, 1999) over a given geographical area. The technique is applied to specific periods in time ("time slices" or "time windows"). GCM results for a given time window include the long-term evolution of climate prior to the chosen time window, based on an incremental increase of greenhouse gases over time. The nested modeling approach represents a trade-off between decadal- or century-scale, high resolution simulations that are today unattainable, even with the most sophisticated computational resources and relying only on coarse resolution results provided by long-term GCM integrations. When driven by analyses and observations, RCMs generally simulate a realistic structure and evolution of synoptic events. Model biases with respect to observations are in the range of a few tenths to a few degrees for temperature and $10-40 \%$ for precipitation. These biases tend to decrease with increasing resolution or decreasing RCM domain size.

Although the method has a number of drawbacks, in particular the fact that the nesting is "one-way" (i.e., the climatic forcing occurs only from the larger to the finer 
scales and not vice versa), RCMs may in some instances improve regional detail of climate processes, particularly when they are driven by measured boundary conditions. This can be an advantage in areas of mountainous terrain, where for example topographically-enhanced precipitation may represent a significant fraction of annual or seasonal rainfall in a particular mountain region. Such improvements are related to the fact that RCM simulations capture the regional detail of forcing elements like topography or large lakes, and the local forcings of such features on regional climate processes, in a more realistic manner than GCMs (BENISTON, 2000). GCM-driven RCMs tend to produce less convincing results, however, which is to be expected since GCMs can generate unreliable results in terms of storm tracks and precipitation belts, for example. As a result, the errors of a GCM will tend to propagate into an RCM. In the example illustrated in Figure 7, results for precipitation and temperature have been compiled by GIORGI et al. (1994) for an RCM operating at $50 \mathrm{~km}$ resolution nested into a GCM with a $300 \mathrm{~km}$ resolution.

The salient differences observed in this illustration are directly related to the enhanced RCM resolution and to the improved regional detail (Fig. 8). In this example, predictions of precipitation changes in Europe show a decrease in a warmer climate according to the GCM simulations and, conversely, an increase in the RCM. This can be explained by the fact that the GCM grid poorly resolves European mountain ranges such as the Alps, the Pyrenees, or the Carpathians, while the RCM is capable of better representing the mountains and thus the enhancement of precipitation which they generate. In other regions, discrepancies between the two climate models are not so important, in part because the orographic effect is either

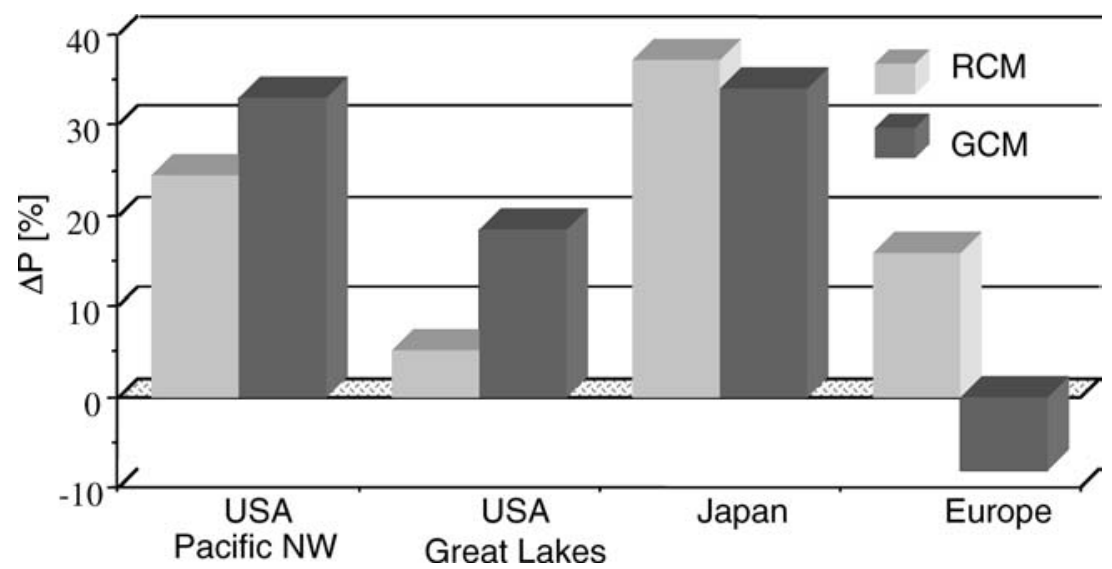

Figure 7

Global (GCM) and regional (RCM) climate model simulations of precipitation change between current climatic conditions and future climate (doubled atmospheric $\mathrm{CO}_{2}$ concentrations) for four regions in the world (BENISTON, 2000). 

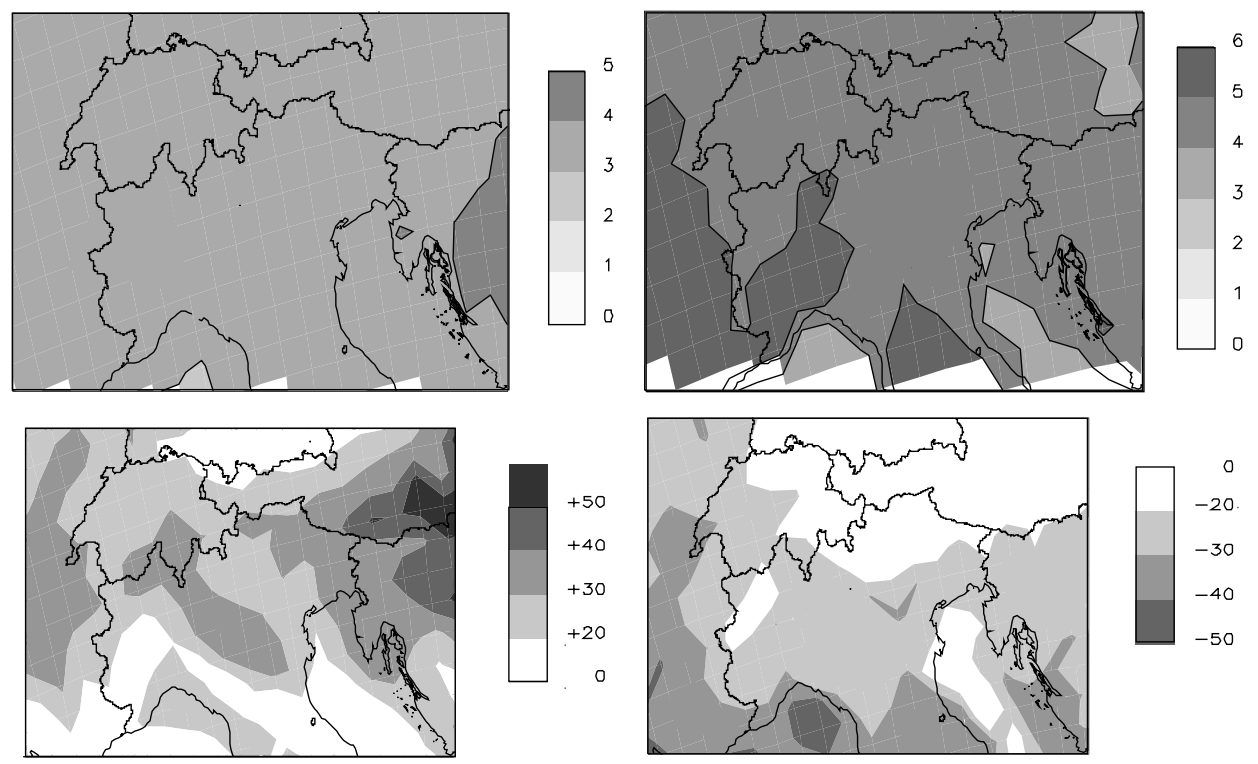

Figure 8

RCM results for climatic change in the Alpine region in the period 2071-2100 compared to the climatological average period 1961-1990. Upper left: Change in mean winter (DJF) temperatures $\left({ }^{\circ} \mathrm{C}\right)$; Upper Right: Change in mean summer (JJA) temperatures $\left({ }^{\circ} \mathrm{C}\right)$. Lower left: Change in mean winter (DJF) precipitation (\%); Lower right: Change in mean summer (JJA) precipitation (\%).

not the dominant factor for precipitation, or because the mountain ranges involved are sufficiently extensive to be adequately resolved in the GCM.

Over time, the increase in spatial resolution of RCMs, that has been enabled by the rapid evolution of computational resources, has enhanced the understanding of regional climate processes and the assessment of the future evolution of regional weather patterns influenced by a changing global climate. MARINUCCI et al. (1995) tested the nested GCM-RCM technique at a $20 \mathrm{~km}$ resolution to assess its adequacy in reproducing the salient features of contemporary climate in the European Alps, while Rotach et al. (1997) repeated the numerical experiments for a scenario of enhanced greenhouse-gas forcing. Over the past five years, RCM spatial resolution has continually increased, partially as a response to the needs of the impacts community. Currently, detailed simulations with $5 \mathrm{~km}$ or even $1 \mathrm{~km}$ grids are used to investigate the details of precipitation in relation to surface runoff, infiltration, and evaporation (e.g., ARNELl, 1999; BERGSTRÖm et al., 2001), extreme events such as precipitation (FrEI et al., 1998), and damaging wind storms (GoYetTE et al., 2001). In its Third Assessment Report, the IPCC (2001) has extensively used the nested modeling technique in an attempt to improve regional climate information. 
As an example of the regionalization of global model results, the nested modeling technique is applied to the European Alps. These results are based on the Hadley Centre (UK) HadCM3 GCM and the HIRHAM RCM of the Danish Meteorological Institute, used in the context of an EU $5^{\text {th }}$ Framework Program project that focuses on future climatic change in Europe (CHRISTENSEN et al., 2002). Although the RCM grid is a relatively coarse $50 \mathrm{~km}$, the results confirm earlier studies by MARINUCCI et al. (1995) and RotACH et al. (1997) which tend to show that alpine climate in the latter part of the $21^{\text {st }}$ century will be characterized by warmer and more humid conditions in winter, and much warmer and drier conditions in the summer, as illustrated in Figure 8.

\section{Conclusions}

Mountains are unique features of the Earth system in terms of their scenery, their climates, their ecosystems; they provide key resources for human activities well beyond their natural boundaries; and they harbor extremely diverse cultures in both the developing and the industrialized world. The protection of mountain environments against the adverse effects of economic development should be a priority for both today's generation and the generations to come (BENISTON, 2000).

The assessment of climatic change and of its related impacts in mountain regions has been shown to be particularly difficult because of the complexity of a number of interrelated factors in regions where topography is a dominant feature of the environment. However, despite numerous uncertainties and issues that still need to be addressed, there is today a large consensus concerning the very real threat which abrupt global warming may pose to a wide range of environmental, social and economic systems both globally and regionally such as in the Alps. The IPCC (1996; 2001) has been instrumental in providing the state-of-the-art information on climatic change and its environmental and economic consequences, so that while science can continue to refine its predictions for the future, our current understanding of the system and its evolution is sufficient to justify international action for reducing the risks related to climatic change and to define strategies for rapidly adapting to change.

In facing up to climatic change, it will be necessary to plan in terms of decades and centuries. Many of the impacts that can be expected on mountain environments related to the amplitude and speed of change may not become unambiguously apparent for several generations. The policies and decisions related to pollution abatement, climatic change, deforestation or desertification would provide opportunities and challenges for the private and public sectors. A carefully selected set of national and international responses aimed at mitigation, adaptation and improvement of knowledge can reduce the risks posed by environmental change to water resources and natural hazards. 


\section{REFERENCES}

Arnell, N. (1999), The Effect of Climate Change on Hydrological Regimes in Europe Global Environ. Change 9, 5-23

BARry, R.G., Past and potential future changes in mountain environments; A review. In (Beniston, M., ed. Routledge Publishing Company, London and New York 1994), Mountain Environments in Changing Climates pp. 3-33.

Becker, A. and Bugmann, H. (1997), Predicting Global Change Impacts on Mountain Hydrology and Ecology: Integrated Catchment Hydrology/Altitudinal Gradient Studies IGBP Report 43, Stockholm.

Beniston, M. (1997), Variations of Snow Depth and Duration in the Swiss Alps over the last 50 Years: Links to Changes in Large-scale Climatic Forcings, Climatic Change 36, 281-300.

Beniston, M. (2000), Environmental Change in Mountains and Uplands. (Arnold/Hodder Publishers, London, UK, and Oxford University Press, New York, USA), 172 pp.

Beniston, M. and Jungo, P. (2002), Shifts in the Distributions of Pressure, Temperature and Moisture in the Alpine Region in Response to the Behavior of the North Atlantic Oscillation, Theor. Appl. Clim. 71, $29-42$.

Beniston, M. and Rebetez, M. (1996), Regional Behavior of Minimum Temperatures in Switzerland for the period 1979-1993, Theor. Appl. Clim. 53, 231-243.

Beniston, M., Diaz, H. F., and Bradley, R. S. (1997), Climatic Change at High Elevation Sites; A Review. Climatic Change 36, 233-251.

Beniston, M., Rebetez, M., Giorgi, F, and Marinucci, M.R. (1994), An Analysis of Regional Climate Change in Switzerland, Theor. Appl. Clim. 49, 135-159.

Bergström, S., Carlsson, B., Gardelin, M., Lindström, G., Pettersson, A., and Rummukainen, M. (2001), Climate Change Impacts on Runoff in Sweden-Assessments by Global Climate Models, Dynamical Downscaling and Hydrological Modelling, Climate Research 16, 101-112.

Christensen, J.H., CArter, T.R., and Giorgi, F. (2002), PRUDENCE Employs New Methods to Assess European Climate Change, EOS, Trans. Am. Geophy. Union 83, 147.

Diaz, H. F. and Bradley, R. S. (1997), Temperature Variations during the Last Century at High Elevation Sites, Climatic Change 36, 253-279.

Ekhart, E. (1948), De la structure de l'atmosphère dans la montagne, La Météorologie 3, 3-26.

Flohn, H. (1968), Contributions to a Meteorology of the Tibetan Highlands, Atmos. Phys. Paper, 130, Dept.of Atmospheric Sciences, Colorado State University, Fort Collins. 120 pp.

Frei, C., Schär, C., Lüthi, D., and Davies, H.C. (1998), , Geophys. Res. Lett. 25, 1431-1434.

Giorgi, F. and Mearns, L.O. (1991), Approaches to the Simulation of Regional Climate Change: A Review. Rev. Geophy 29, 191-216.

Giorgi, F. and Mearns, L. O. (1999), Regional Climate Modeling Revisited. J. Geophys. Res. 104, 63356352.

Giorgi, F., Brodeur, C.S., and Bates, G.T. (1994), Regional Climate Change Scenarios over the United States Produced with a Nested Regional Climate Model. J. Clim. 7, 375-399.

Giorgi, F., Hurrell, J., Marinucci, M., and Beniston, M. (1997), Height Dependency of the North Atlantic Oscillation Index. Observational and Model Studies, J. Clim. 10, 288-296.

Goyette, S., Beniston, M., Jungo, P., Caya, D., and Laprise, R. (2001), Numerical Investigation of an Extreme Storm with the Canadian Regional Climate Model: The Case Study of Windstorm Vivian, Switzerland, February 27, 1990, Climate Dynamics 18, 145-168.

Grassl, H., The Alps under local, regional and global pressures. In Mountain Environments in Changing Climates (Beniston, M., ed. Routledge Publishing Company, London and New York 1994), pp. 34-41.

Hurrell, J. W. (1995), Decadal Trends in the North Atlantic Oscillation Regional Temperatures and Precipitation, Science 269, 676-679.

Hurrell, J. W., and van Loon, H. (1997), Decadal Variations in Climate Associated with the North Atlantic Oscillation, Climatic Change 36, 301-326.

IPCC (1996), Climate Change. The IPCC Second Assessment Report. Cambridge University Press, Cambridge and New York. Volumes I (Science), II (Impacts) and III (Socio-economic implications).

IPCC (2001), Climate Change. The IPCC Third Assessment Report. Cambridge University Press, Cambridge and New York. 
Jones, P.D. and Moberg, A. (2003), Hemispheric and Large-scale Surface Air Temperature Variations: An Extensive Revision and an Update to 2001, J. Climate 16, 206-223.

Jungo, P., and Beniston, M. (2001), Changes in 20th Century Extreme Temperature Anomalies at Swiss Climatological Stations Located at Different Latitudes and Altitudes, Theor. Appl. Clim. 69, 1-12.

Kapos, V., Rhind, J., Edwards, M., Ravilious, C., and Price, M. (2000), Developing a map of the world's mountain forests. In Forests in a Sustainable Mountain Environment. (Price, M.F. and Butt, N., eds.),(CAB International, Wallingford 2000)

KLÖTZLI, F. (1994), Vegetation als Spielball naturgegebener Bauherren, Phytocoenologia 24, 667-675.

Marinucci, M. R., Giorgi, F., Beniston, M., Wild, M., Tschuck, P., and Bernasconi, A. (1995), High Resolution Simulations of January and July Climate over the Western Alpine Region with a Nested Regional Modeling System, Theor. Appl. Clim. 51, 119-138.

Meybeck, M., Green, P., and Vörösmarty, C. (2001), A New Typology for Mountains and other Relief Classes: An Application to Global Continental Water Resources and Population Distribution, Mountain Res. Develop 21, 34-45.

Ozenda, P. (1985), La végétation de la chaîne alpine dans l'espace montagnard européen, Masson, Paris, 344 pp.

Quezel, P. and BARBero, M. (1990), Les forêts méditerranéennes: problèmes posés par leur signification historique, écologique et leur conservation, Acta Botanica Malacitana 15, 145-178.

Rameau, J.C., Mansion, D., Dumé, G., Lecointe, A., Timbal, J., Dupont, P.,and Keller, R. (1993), Flore Forestière Francaise, Guide Ecologique Illustré. Lavoisier TEC and DOC Diffusion, Paris, 2419 pp.

Rogers, J. C. (1997), North Atlantic Storm Track Variability and its Association to the North Atlantic Oscillation and Climate Variability of Northern Europe, J. Climate 10, 1635-1647.

Rotach, M., Wild, M., Tschuck, P., Beniston, M., and Marinucci, M. R. (1997), A Double CO, Experiment over the Alpine Region with a Nested GCM-LAM Modeling Approach, Theor.Appl. Clim. 57, 209-227.

SCHNeIDER, U. (1992), Die Verteilung des troposphärischen Ozons in Bayrischen Nordalpenraum, Ph.D. Dissertation, University of Mainz, Germany.

Serreze, M. C., Carse, F., Barry, R. G., and Rogers, J. C. (1997), Icelandic Low Cyclone Activity: Climatological Features, Linkages with the North Atlantic Oscillation, and Relationships with Recent Changes in the Northern Hemisphere Circulation, J. Climate 10, 453-464.

Smidt, S. (1991), Messungen nasser Freilanddepositionen der Förstlichen Bundesversuchsanstalt, FBVABerichte, ISSN 1013-0713 50, Nasse Deposition, Austria.

Wade, L. K. and McVean, D. N. , Mt. Wilhelm Studies; The Alpine and Subalpine Vegetation (Australian National University, Canberra 1969), 225 pp.

Wanner, H., Rickli, R., Salvisberg, E., Schmutz, C., and Schuepp, M. (1997), Global Climate Change and Variability and its Influence on Alpine Climate-Concepts and Observations, Theor. Appl. Climatology 58, 221-243.

Wardle, P. (1973), New Zealand Timberlines, Arctic and Alpine Res. 5, 127-136.

Zorita, E. and von Storch H. (1999), The Analog Method-A Simple Statistical Downscaling Technique: Comparison with more Complicated Methods, J. Climate 12, 2474-2489.

(Received May 27, 2003, accepted January 21, 2004)

Published Online First: May 252005

To access this journal online:
http://www.birkhauser.ch 